\title{
Science Journalism as an Academic Discipline: the Fusion of Western Media and Science seen from a Literary and Social Perspective
}

\author{
Autor \\ Dr. Carlos Elías \\ Catedrático de Periodismo Científico. \\ http://orcid.org/0000-0002-1330-4324 \\ Universidad Carlos III de Madrid. \\ Universidad Nacional de Educación a Distancia \\ carlos.elias@uc3m.es
}

\begin{abstract}
Science Journalism addresses the intersection of two major spheres of Western culture: natural sciences and mass media. And both can be said to share the same ultimate goal: to seek the truth and make it public. On the other hand, Science Journalism is a creative writing between Natural and Social Sciences and, as a profession, is the perfect bridge between the two cultures -scientific and literary- defined by C.P. Snow. It is therefore, a rich discipline in every aspect, but also one that involves a great deal of conceptual and procedural complexity. Journalism is the craft of creative writing, and initially, science also adapted a literary style. Scientific Journalism deals exclusively with Natural Science, but with a Social Sciences point of view. It requires similar standards and guidelines, such as those used by scientists -physicists, chemists, biologists and geologists- for a journalist to approach the facts. In scientific journalism it is important to define what is theory in Natural Science as opposed to the Social Sciences. "Science" journalism deals with information that comes exclusively from discoveries and facts. Science journalism, as a profession, is the perfect bridge between these two cultures: scientific and literary. A science journalist has more close contact with scientists -and their scientific results- than a sociologist or philosopher of science. But at the same time, journalism is a literary genre itself.
\end{abstract}

Key words: Science Journalism, Creative Writing, Popular Science, Two Cultures. 


\section{Introduction}

Science Communication as academic subject is not a very old discipline. In 1988, the Australian National University in Canberra had started what Brian Trench identifies as the world's first science communication Master's course, and in the United States, a number of courses specialised in science journalism (Trench, 2012). In the UK, Imperial's MSc in Science Communication was started by John Durant, who then held a joint appointment as the UK's first Professor of the Public Understanding of Science at Imperial College and as Assistant Director and Head of Science Communication at the neighbouring Science Museum in London (Durant, 2012). Among other ideas he suggested a Master's programme. The application was successful and preparation began to launch the new course in autumn 1991. Although science communication was not yet widely taught, there were already some similar courses from which Durant and his colleagues could take some inspiration (Mellor, 2013).

According to Brian Trench, senior lecture in The School of Communication at Dublin City University, over the past quarter of a century, science communication as a subject has emerged in universities across the world. In many countries, on several continents, at widely differing institutions, science communication has become a recognized subject of individual courses in broader science programmes or of denominated degree programmes at bachelor's and (mainly) master's levels. The spread of these programmes since the mid-1980s parallels the staging of international conferences on the public communication of science and technology and the foundation and repurposing of academic journals to cover this field (Trench, 2012). Publication of handbooks, textbooks and other collected volumes, which has intensified since the late 2000s, both reflects the growth of taught programmes and promotes the field (see, for example, in English: Bennett \& Jennings 2011; Bucchi \& Trench 2008; Brake \& Weitkamp 2010; Cheng et al. 2008; Holliman et al. 2009; Kahlor \& Stout 2009; and in Spanish: Elías, 2008, 2014). "The increasing research activity, reflected in the number of doctorates in this field -also spread across several continents and many countries- represents the consolidation of science communication as a university subject (Trench, 2012)".

In Spain, 2010 it was the first time that a Chair in Journalism (the highest Spanish academic level) was won by someone who came from science communication research area. To win the chair not only implies to pass a previous stage in which a national committee evaluates candidates' merits through a highly demanding blind process (in Spanish acreditación); but involves the duty to develop a new course: it has to be innovative with other approach from similar subjects.

According to Susanna Priest, professor at University of Nevada,

"the term 'science communication' refers both to a range of related fields of professional practice and to an interdisciplinary field of study. The fields of practice (from the design of museum exhibits to the practice of science journalism and the conduct of science-oriented public information, public outreach, public engagement, and public relations activities) all involve active attempts to communicate scientific subject matter to a variety of broader publics (Priest, 2010: 1)".

So there is a big difference between science communication and science journalism. This essay seeks to establish several guidelines for the establishment of this academic subject: "Science 
Journalism" as a separate discipline from "Science Communication". On the other hand, print journalism as a whole is facing new pressures with the rise of online journalism. A recent study of the global state of science journalism found that although $75 \%$ of science journalists thought claims about 'the death of journalism' were exaggerated, $78 \%$ felt the internet was changing journalism (Bauer et al., 2013)

\section{Science and Journalism: to seek the truth and make it public}

Journalism and Science speak two very different languages. The former claims a place in literature while the second aims at a universal language centered in mathematics suggested by Leibnitz in the seventeenth century. Yet these differences cannot overshadow the enormous similarities shared by both disciplines; for both science and journalism are products of Western culture. The Chinese, for example, learn the Latin alphabet to study chemistry, and Arabic for numbers - not just to understand algebra, but for the sophistication that comes with technology and mathematics.

Journalism came into being at the same time as modern science when, in the seventeenth century, the philosopher Francis Bacon (1561-1626) began a revolution in the form of attaining knowledge which was not based on the accepted wisdom of a hierarchy or authority but instead on direct observation. His emphasis on accurate observation, especially in detailing facts, is what lies at the heart of "science" journalism, which originated around the same time or not long afterwards: the Royal Society, the first institution dedicated to science, was founded in 1660 , and the first newspaper, the Daily Courant, in 1702. Both these institutions and professions flourished free from the interference of power, whether it was economic, political or religious, and both can be said to share the same ultimate goal: to seek the truth and make it public.

Galileo Galilei (1564 -1642) may rightly be called the first modern scientist. Yet despite his achievements, what was key was the creation of the Scientific Method, namely observation and experimentation and the reproducibility of results which could in turn be made known to a wider audience (and subsequently published by the Royal Society). Galileo used Italian and Latin - the language of common worship of the time - to spread his achievements. For both method and communication are fundamental to modern science: what is not written down and referenced is not science. It is the same notion which underlines journalism and mass newspapers since similarities can be found between scientific method and the steps taken to verify news which make the two disciplines mutually supportive.

Therefore it comes as no surprise that countries with higher research and a scientific tradition also possess a higher standard of journalism. Australia and Mexico both have Nobel Prize winners for Literature, Patrick White and Octavio Paz respectively. In 2015, Mexico had a population of 119 million and Australia 23. Mexico is richer than Australia: according to the International Monetary Fund (2014) Mexico was the eleventh largest economy in the world and Australia the nineteenth. Mexico however had only one Nobel Prize in science and Australia eight, suggesting it is no mere coincidence that newspapers are so powerful and influential there. Mexico, on the other hand, is one of the countries where most journalists are killed for practicing their profession. 
Democracy, freedom and a culture of science and reason are fundamental to good journalism. In Europe, German and British journalism has a much better quality rating than its Italian or Spanish counterparts. Although all of them are EU countries and democratic, nevertheless Germany and Britain have a stronger scientific tradition, having more scientists and Nobel Prize winners than the others.

\section{Science Journalism: a creative writing between Natural and Social Sciences}

Journalism is the craft of creative writing, and initially, science also adapted a literary style. Galileo's success as an author was in fact more important than his actual scientific achievement, since it was his literary talent that allowed for mass dissemination of his "Dialogues", which became a bestselling success and led to him being denounced to the Inquisition. Galileo's achievement was a masterclass in Italian "science" journalism, while in more liberal England, the Royal Society and scientific journals flourished.

It is clear that both disciplines have much in common and between these two defining areas of culture there is a point where they intersect, the point where journalism looks to science. This opens up a potentially new field for teaching and research in the area of "science" journalism. In Spain there are 77 universities (both public and private) of which 32 offer a degree in Journalism. Of these, in 16, science journalism is a taught subject (Elías y Luengo, 2014). The course is designed not to train science journalists since these require postgraduate study, but for students to acquire a general vision of what science journalism is. In undergraduate studies, the public communication of science is only taught in Spain in journalism studies and its presence in philosophy, science, or sociology is somewhat anecdotal.

From the professional point of view, the subject aims to provide the future journalist with a minimum of skills to acquire if in the course of their professional life they are to report on science and technology. Moreover, it also aims to inspire a future vocation in science journalism and research in the discipline.

The Dictionary of the Royal Spanish Academy (DRAE), in its twenty- second edition, defines science as a set of knowledge obtained through observation and reasoning, systematically structured and deduced by general principles and laws. Under this broad definition, economics, sociology, pedagogy, politics and even journalism itself could be considered a science. Scientific Journalism deals exclusively with Natural Science, but with a Social Sciences point of view. It requires similar standards and guidelines, such as those used by scientists -physicists, chemists, biologists and geologists- for a journalist to approach the facts. In scientific journalism it is important to define what is theory in Natural Science as opposed to the Social Sciences.

For example, the emphasis in Social Sciences is on things that frequently occur. In 2013 Nobel Prize for Economics went to two economists who contradicted one another. (It must be pointed out here that the Nobel Prize for Economics is funded by banks, as opposed to the others, in other words, a fund with a particular interest). Eugene Fama received the Prize for "proving" the rationality of the markets while Robert Shiller shared it for "proving" exactly the opposite: that investors behave irrationally. So where does this leave the journalist? What conclusions can he or she draw? The answer lies in the ideology of their medium. 
This would never happen with the Natural Sciences. Nobody receives a Nobel Prize (such as James Chadwick in 1935) for proving the existence of neutrons and another for proving the opposite. If a journalist writes that atoms do not exist, they are in the realm of pseudoscience and 'anti-journalism.' The very existence of the atom, for example, contradicts dogma such as transubstantiation in Catholic Church teaching.

In the Scientific, or 'Science' Journalism program, students learn the deep distinctions between how both operate; what is scientific truth in natural science and more often than not, opinion in social science. This is why it is advantageous for teachers of scientific journalism to be doubly trained at third level, with one degree in a natural science and the other in humanities and/or social sciences. This "double training" is desirable -but not absolutely essential- to teach the subject. However, it is very convenient to demonstrate prior experience working as a science journalist in media.

Environmental journalism may be approached from a scientific or political viewpoint. If we opt for the scientific, demonstrable facts are essential. If it is 'political', then we can add comments from economists, sociologists and geographers. In 1995, Mario Molina, Frank Kowland and Paul Crutzen received the Nobel Prize for Chemistry for demonstrating the (harmful) effects of chlorofluocarbons massively used in industry on the disappearance of the ozone layer. A 'science' journalist could never write an article that contradicted the proofs of these Nobel laureates. On the other hand, an 'economic' journalist might opt for the theory that best suits his medium when it comes to deciding how rationality affects the markets. He might opt for Fama, or Shiller, or even both, and by so doing the article misinforms instead of informing, since the reader does not know what to expect.

A scientific journalist could never be in favour of homeopathy or against the effect of carbon dioxide on climate change. In short, 'science' journalism in the university teaches that scientific journalists deal with proven, and never contradictory facts while those who deal with economics, sociology, politics and history more often than not avail of theories from the social sciences to support ideological opinions.

"Science" journalism deals with information that comes exclusively from discoveries and facts. Since this a rather strict definition, there are discussions among academics whether specialist healthcare, environmental issues or technological advances should also be included in the terms of scientific journalism. The general opinion would appear to be that there is a practical application of general laws and procedures which are the same as those used in science journalism. As a result (although in some cases requiring minor adaptations), the fundamentals are the same as those for covering biology or physics.

In fact, the guidelines which obligate science journalism to only concern itself with published results are being continually revised in health, environmental and technological spheres. The general principles of journalism that address the natural sciences should also govern the reporting of health, the environment and technology, since these are three of the most important areas of our survival as a species. 


\section{Differences between journalism and popular science}

Can Richard Dawkins and David Attenborough be called science journalists? Strictly speaking, the answer is no, for they are not even professional scientists. They are disseminators, making science understandable. Was Sir Kenneth Clark, presenter and writer of the BBC series Civilization, a "culture" journalist? Clark, Professor of Art History and director of the National Gallery of London, was an expert but he neither painted nor built cathedrals. The reporter, like an artist, scientist or writer constructs a worldview which he then disseminates. It is this creative spirit, therefore, which pervades science journalism, not simply the public communication of science and social development.

Dictionaries define "public communication" as publishing or disseminating knowledge to the public. The problem is that they do not define who or what that public is. For example, is peer communication among scientists on a research paper -a community with thousands of members- to be considered disclosure?

Journalism has to be a means of mass communication and at the same time question the authority of sources. Science uses aseptic language because it is the data which convinces and not the style, whereas Journalism is a persuasive tool that uses the full potential of rhetoric from synonymy to metaphor and analogy - to convince. Besides, journalism is not just public communication (which might be said for the journal Nature) but a watchdog with a massive general audience.

Disseminators too, also aspire to mass audiences. Attenborough enjoys a huge audience because of his outstanding documentaries on the BBC. Rhetoric and image are used as persuasive elements, often influencing scientists to share or imitate the popularizers' work patterns. But the approach is very different when dealing with scientific information, the basic difference between popular science and science journalism being that the latter always names its sources (in this case, scientists ) and therefore, aims to provide some benefit for the environment of the source. Disclosure can sometimes occur in science journalism, but that is not the end in itself. Journalists have to contextualize whether, for example, an experiment is socially worthwhile or if it might be necessary to remove funding for programs. Consequently they seek to highlight wider social concerns rather than the actual source.

Popularizers like Carl Sagan, Richard Attenborough and Richard Dawkins, all use popular science as a tool to attract more brains and funding, or simply to proselytize scientific thinking. In this atmosphere it is difficult for a scientist to be critical if there is a perceived - popular need to invest billions of euros in a new space telescope, for example. The reality is that for most scientists, any money to invest in their field, especially in research, will always be scarce. However, a journalist should be thorough and analyze issues that go beyond simple disclosure, including the proper use of public money for science, ethical behavior and professional scientific or meaning (or sometimes irrelevance) of scientific results that will "sell" what the researchers said. A journalist should always be critical and skeptical of popularization.

The frame of reference for communicators and journalists is also different. A particularly relevant definition of journalism given by Eugenio Scalfari (director of "La Repubblica") is "the purpose of journalism is to tell the people what is happening to the people." When we talk about a natural disaster, a food shortage or a technological failure, we are talking journalism. But if a 
report were to be made on the origin of the universe or how the sun's magnetic field influences sunspots, obviously, that implies disclosure of sources.

A story has to be customized in order to make it journalistic. If we expand on the preceding anecdote and add that the consequence of such solar activity affected satellites and mobile communications with consequent disruption across the globe, then we go back into the field of journalism, because we are narrating "what happens to the people."

For most journalists what is of importance in this case is that people cannot use their mobile phones, and by extension the report should include a breakdown explaining nuclear fusion in the sun, how magnetic fields, sunspots and storms are formed in which ejected particles affect satellites. And the journalist may also need to report the impact on financial markets and other human interest stories, etc.

But for the scientist or disseminator the main thing is not that the satellites do not work, nor the mobile phones either. From their perspective it is important to explain why at given cycles the sun begins to throw out so many space particles. Why sunspots exist, how they form, why they disappear, how matter flows and magnetic fields operate, how long the Sun will continue in this cycle and what will happen next. Now if they wish that information to reach a mass audience, the reporter must use professional journalistic techniques, though their references and their interests do not necessarily coincide. Therefore, the scientist or reporter must assume that media may not always accept their "disinterested" efforts, especially if they do not have "what happens to people" in them.

\section{Conclusion: The "Two Cultures" and Science Journalism as the "Third Culture"}

There is a joke about a harried checkout clerk in a supermarket in Central Square, Cambridge, midway between MIT and Harvard. She is working at the counter marked by a prominent red sign, "Express lane-twelve items only," she sees an unmistakable student type approaching with a shopping cart heaped high with dozens of packages. "Listen buster," she blurts out with patronizing exasperation, "I don't know whether you go to MIT and don't read, or to Harvard and can't count, but [with emphatic derision] you are in the wrong line!" A science journalism student had chosen the correct line.

The British scientist -and novelist- C.P.Snow published in 1959 his provocative The Two Cultures: a controversial attack on the divisions between the worlds of arts and science in Western society:

"I believe the intellectual life of the whole of western society is increasingly being split into two polar groups. When I say the intellectual life, I mean to include also a large part of our practical life, because I should be the last person to suggest the two can at the deepest level be distinguished.... Two polar groups, at one pole we have literary intellectuals, who incidentally while no one was looking took to referring to themselves as 'intellectuals' as though there were no others. . . I remember G.H. Hardy once remarking to me in mild puzzlement, some time in the 1930's: 'Have you noticed how the word "intellectual" is used nowadays?' There seems to be a new definition which certainly doesn't include Rutherford, or Eddington or Dirac or Adrian or me. It does seem rather 
odd don't you know. Literary intellectuals at one pole-at the other scientists, and as the most representative, the physical scientists. Between the two a gulf of mutual incomprehension-sometimes (particularly among the young) hostility and dislike, but most of all lack of understanding. They have a curious distorted image of each other. (Snow, 1961: 11-12)"

Science journalism, as a profession, is the perfect bridge between these two cultures: scientific and literary. A science journalist has more close contact with scientists -and their scientific results- than a sociologist, historian or philosopher of science. But at the same time, journalism is a literary genre itself. I mean: science journalists never write boring papers such as sociologists, historians or philosophers of science use to do. Science journalists need exciting creative writing to captivate and engage the audience. And, in some sense, they create art, a type of literature, which in the future will be studied by sociologists, philosophers or historians.

Scientists who engage in disclosure are infamous among their colleagues. In 1940 the British mathematician Godfrey Hardy in A Mathematician's Apology argued that scientists were first-rate intelligentia and popularizers of science were second. CP Snow describes A Mathematician's Apology as "a passionate lament for creative powers that used to be and which will never come again". In Hardy's words,

"It is a melancholy experience for a professional mathematician to find himself writing about mathematics. The function of a mathematician is to do something, to prove new theorems, to add to mathematics, and not to talk about what he or other mathematicians have done. Statesmen despise publicists, painters despise art-critics, and physiologists, physicists, or mathematicians have usually similar feelings: there is no scorn more profound, or on the whole more justifiable, than that of the men who make for the men who explain. Exposition, criticism, appreciation, is work for second-rate minds. (Hardy, 1940: 1)"

Hardy, a brilliant mathematician and creator of theorems, apologized for writing a popular book. "Because I write about mathematics, like any other mathematician who has passed sixty, I not have longer the freshness of mind, the energy, or the patience to carry on effectively with my proper job."

A Mathematician's Apology has had a great influence on science and its organization since World War II. Its main idea is still in force among most scientists, namely that someone who is brilliant produces science, not science reports produced by another; something similar to the difference between the writer and the literary critic. Embittered critics cannot be creators themselves, and have had to settle for the 'crumbs' of interpreting true geniuses and their works.

This notion is crucial, because in our journalism and film schools (in Spain), unlike literature or cultural studies, we train students not to study what others have created. We hope that they become creators themselves in journalistic literature; that they configure their own view of the world. This creates a fundamental difference between the contents of science journalism and other subjects taught in the Anglo-Saxon manner on science and society, sociology of science or public communication of science. Science journalists might be defined as those who create information in print, web or television for study and analysis by society experts. 
A journalist is not just a writer either. A journalist in his /her report, chronicle, story, etc. - should always reference the source: that is, they have an obligation to explain why, at a given time, the scientific source should use the media or why in other cases not talk to a scientist. In this sense, science journalism should not be different from political or economic journalism.

Science journalism is much more complex than popular science, and it should not only include the latter but reference and contextualize it. The difference depends on the professional viewpoint from which they approach the issue. From the point of view of the message, the reporter must have sufficient scientific evidence to understand what sources say, and above all, interpret the context in which they say it. The journalist has to be an expert on sources. In fact, a significant percentage of the journalism course in Spain deals with different sources, including scientific journals, NASA, universities, The Royal Society, etc. . But it also needs be aware of controversial issues such as genetic modification, climate change, nanotechnology, biotechnology, and what will always be news: the Universe, Mars, Life, Zoology, etc....

A communicator can know the exact definition of atom and molecule or phenotype and genotype, but not know the difference between a scientist funded by a university and another belonging to a public research organization whose head might well be a politician. A popularizer does not have to go deeply into the difference between information published in the journal Nature and that provided by the press office of NASA.

The popularizer is looking for the source to obtain the necessary scientific discovery to build his argument. The reporter also, although they cannot ignore other factors, such as cost, who benefits, why they have decided to go public, who has the power relations with a given political or economic power, how and where it obtained the finding and if it might harm someone or something. The media coverage of science is much more complete than simple popular science because it requires an explanation of the causes and circumstances of the event itself and this can only be achieved with proper journalistic and scientific editorial practice.

The popularization of science however does not need to establish relationships with fact. A film or documentary about the Sun or the African Savannah has no relation to time. In fact, television constantly replenishes the media popularization of science. In this case it is the union of disclosure or explanation of pure scientific concepts. For example, if a report describes how the Canary Islands Telescope works (Gran Telescopio Canarias or GTC) - considered one of the most important scientific facilities Spain - disclosure will be talking about natural science. If the data is focused exclusively on the galaxy or extrasolar planets detected by the telescope, then this information too will be disclosed.

But if an article is published that analyzes different sources such as the cost of the facility or the need for having space telescopes at all , then this will be a newspaper article, as will all that address accounting irregularities or management of the facility. This type of reporting never addresses scientists and usually tries to correspond with reporters exclusively. When it comes to combining the two, ( both in the same article), such as, for example, one day a more scientific approach is chosen and the next one that is more political or sociological or economic, this is disclosure of a journalistic kind and makes scientific journalism informative. But the word 'journalism' should be used only if there is a well-defined watchdog present. 


\section{References}

- $\quad$ Bauer MW, Howard S, Ramos YJR, Massarani L and Amorim L (2013) Global Science Journalism Report: Working Conditions \& Practices, Professional Ethos and Future Expectations. London: SciDev.Net.

- $\quad$ Bell, A.R., Davies, S.R. \& Mellor, F. (eds) (2008). Science and its publics. Newcastle: Cambridge Scholars Publishing.

- $\quad$ Bennett, D.J. \& Jennings, R.C. (eds) (2011). Successful science communication: Telling it like it is. Cambridge: Cambridge University Press.

- $\quad$ Brake, M.L. \& Weitkamp, E. (eds) (2010). Introducing science communication: A practical guide. Houndsmills, Hants: Palgrave Macmillan.

- $\quad$ Bucchi, M. \& Trench, B. (eds) (2008). Handbook of public communication of science and technology. London: Routledge.

- Cheng, D., Claessens, M., Gascoigne, T., Metcalfe, J., Schiele, B. \& Shi, S. (eds.) (2008). Communicating science in social contexts. Dordrecht: Springer.

- Durant J (2012) Plenary Address. Science Communication MSc 21st Anniversary Conference, Imperial College, 13 September.

- Elías, Carlos y Luego, María (2014). "Periodismo Especializado y áreas de especialización en el currículo de los Grados de Periodismo en las Universidades españolas" en Nuevos retos del Periodismo Especializado (Francisco Esteve y Juan Carlos Nieto eds). Sheidas. Madrid.

- Elías, C. $(2008,2014)$. Fundamentos de periodismo científico y divulgación mediática. Madrid: Alianza Editorial.

- Hardy, G.H. (1940). A Mathematician's Apology. Cambridge: Cambridge University Press.

- Holliman, R. et al. (eds) (2009), Practising science communication in the information age: Theorising professional practices. Oxford: Oxford University Press.

- Kahlor, L.E. \& Stout, P. (eds) (2009). Communicating science: New agendas in communication. London: Routledge.

- Mellor, F. (2013). "Twenty years of teaching science communication: A case study of Imperial College's Master's programme". Public Understanding of Science. 22(8) 916-926.

- Priest, S.H. (2010). Coming of age in the academy? The status of our emerging field. Journal of Science Communication, 9, 3.

- Snow, C.P. (1961). The Two Cultures and The Scientific Revolution. Cambridge: Cambridge University Press.

- Trench B (2012) "Vital and vulnerable: Science communication as a university subject." In: Schiele B, Claessens M and Shi S (eds) Science Communication in the World: Practices, Theories and Trends. Dordrecht: Springer, pp. 241-258.

\section{CURRICULUM VITAE}

CARLOS ELÍAS is Full Professor of Journalism at UNED and Universidad Carlos III de Madrid. He also was visiting scholar at Harvard and London School of Economics. While at Harvard he wrote his latest book, El selfie de Galileo (Península/Planeta 2015), where he analyses the deep relationship between science and technology with the present social and political changes. He was chemistry researcher before working as a political journalist for EFE News Agency and as science correspondent for El Mundo. Educated in Chemistry and Journalism, his thesis in Science Communication was awarded as the best in Social Sciences (Universidad de La Laguna). 